\title{
Nutritional Status and Associated Factors in Institutionalized Elderly
}

\section{Costa Bruna Vieira de Lima', Fonseca Leorges Moraes ${ }^{2}$ and Lopes Aline Cristine Souza ${ }^{3 *}$}

${ }^{1}$ Nutricionista Ph.D. in Nursing and Health School of Nursing, Federal University of Minas Gerais (UFMG) and Research Group in Nutrition Interventions - GIN, Brazil ${ }^{2}$ Professor, Department of Technology and Inspection of Animal Products, School of Veterinary Medicine, Brazil

${ }^{3}$ Department of Maternal-Child Nursing and Public Health - Nursing School - UFMG, Research Group in Nutrition Interventions - GIN, Centre for Urban Health and Center for Studies in Public Health and Aging - NESPE, Brazil

\begin{abstract}
Peculiar situations due to physiological changes of aging, the diseases present and psychosocial factors and dietary factors can influence the nutritional status of the elderly. The purpose was to identify nutritional status and associated factors among elderly residents of a long-term institution for the elderly in Belo Horizonte-MG. Sectional study conducted using a representative random sample. Socioeconomic data, nutrient intake and anthropometry were collected and a Mini Nutritional Assessment was conducted. The analysis employed multinomial logistic regression and decision trees. There was high prevalence of overweight $(46.1 \%)$ among subjects, according to body mass index, as well as risk of malnutrition, according to the Mini Nutritional Assessment (67.3\%), and inadequate intake of nutrients. In the decision tree analysis, it was found that the more independent elderly, who received visits and contributed financially less to the institution, had better nutritional status. Inadequate nutritional status associated with social conditions and mobility indicates the need to promote healthy eating habits by a nutrition team in conjunction with nursing staff and other professionals providing comprehensive health care for the elderly.
\end{abstract}

Keywords: Aged; Elderly nutrition; Food consumption; Homes for the aged; Malnutrition; Obesity

\section{Introduction}

The elderly are characterized by unique conditions as a result of physiological changes characteristic of aging, as well as diseases and psychosocial and dietary factors that influence their nutritional status [1].

In general, the elderly are at increased risk of malnutrition due to insufficient food intake (amount) and poor selection of food (quality). This situation is aggravated when institutionalized, the occurrence of nutritional disorders in institutionalized elderly ranging from $30 \%$ to $80 \%$, with a consequent negative impact on their health [2].

In a study aiming to investigate the nutritional status of residents of five long-stay institutions for the elderly (ILPI), the risk of malnutrition was $37.5 \%$ among older females and $43.7 \%$ among the elderly males, with malnutrition more prevalent among women (12.5\% vs. $6.2 \%)$ [3]. Using a Mini Nutritional Assessment (MNA), another study conducted in Rio de Janeiro showed that $8.3 \%$ of institutionalized elderly were suffering from malnutrition, while $55.6 \%$ were at risk [4].

Regarding the consumption of nutrients, a study conducted with participants in the Family Health Program in Vitória, Espírito Santo, revealed a high prevalence $(80 \%)$ of inadequate intake of nutrients [5]. Examining nutrients such as vitamin $\mathrm{C}$, iron and protein revealed respectively an inadequacy of $44.8 \%, 15.9 \%$ and $14.6 \%$. Another study to assess iron intake in institutionalized elderly, found that $98 \%$ of the elderly males and $89 \%$ of the females were consuming more than the recommended intake. Yet zinc intake was in adequate in $100 \%$ of the elderly males and $98.5 \%$ of the females [6].

A deficiency of such nutrients can compromise the health of the elderly, leading to loss of muscle mass, poor wound healing, depression, reduced memory and dementia, situations which are aggravated by the presence of malnutrition [1]. In contrast, inadequate consumption of calories and lipids can contribute to a higher occurrence of excess weight, a condition also prevalent in this group, as well as cardiovascular diseases, neoplasm and other disorders [1].

Given the influence and importance of the nutritional health of older people, especially those who are institutionalized, this article examines the nutritional status and associated factors in a representative sample of elderly residents of a long-term philanthropic institution in Belo Horizonte, Minas Gerais.

\section{Materials and Methods}

This is a cross-sectional study of elderly people aged 60 years and over, of both sexes, living in an ILPI in Belo Horizonte, Minas Gerais. Of the 94 elderly were randomly selected 55 people over 60 years, based on $99 \%$ of explanatory power $(n=35)$ and $30 \%$ loss $(n=55)$. The sample was simply random, comprised of 52 elderly patients, since three gave up to participate, however, representing $55.3 \%$ of the total.

The ILPI under study is a philanthropic entity with an agreement with the Municipal Office of Food and Nutrition Safety in Belo Horizonte for the supply of foodstuffs. It has a nutritionist on staff responsible for the quality of meals produced and nutrition of the elderly, as well as a multidisciplinary team comprised of nurse, physiotherapist, speech therapist, social worker, psychologist, pharmacist, occupational therapist, nursing staff and caregivers.

Data collection consisted of information obtained from medical records, relating to age, sex, marital status, whether the resident had children, the occurrence of chronic diseases and level of education. The use of dental prosthesis was established based on information provided by the ILPI staff, as well as direct observation. The variables frequency of visits / family participation and financial contribution were obtained from the institution's records. In addition, anthropometric

${ }^{*}$ Corresponding author: Aline Cristine Souza Lopes, School of Nursing, Department of Maternal-Child Nursing and Public Health, Avenida Alfredo Balena 190, 4th Floor, Room 420, Santa Iphigenia, CEP 30130-100, Belo Horizonte, Minas Gerais, Brazil, Tel / fax: 31 3409-9179 / 3409-9860; E-mail: aline@enf.ufmg.br

Received April 10, 2012; Accepted June 26, 2012; Published June 28, 2012

Citation: de Lima CBV, Moraes FL, Cristine Souza LA (2012) Nutritional Status and Associated Factors in Institutionalized Elderly. J Nutr Disorders Ther 2:116. doi:10.4172/2161-0509.1000116

Copyright: (c) 2012 de Lima CBV, et al. This is an open-access article distributed under the terms of the Creative Commons Attribution License, which permits unrestricted use, distribution, and reproduction in any medium, provided the original author and source are credited. 
measurements were collected, and information referring to the MNA and three-day food record was collected.

For the anthropometric evaluation, the following variables were used: Body mass index (BMI), calf (CP), arm (AC), waist (WC) and Hip circumference (HC), Waist / hip ratio (WHR), Triceps skinfold (TSF) and adjusted arm muscle area $(\mathrm{AMBc})$. All measurements were obtained in accordance with recommendations [7], and the anthropometric variables were evaluated three times, and an average obtained.

The height and weight of the elderly who showed postural instability, or who were bedridden, was obtained from knee height and an equation that combines anthropometric data, respectively [8].

The cut-off points adopted for adjusting BMI were those proposed [9], while the WC and WHR values were compared with the cutoff set [7]. The estimation of $\mathrm{AMBc}$ was performed using the equations proposed [10] and classified according to the percentiles [11]. The circumference of the calf was determined in accordance with recommendations [12]

For the diagnosis of risk and malnutrition, particularly in the elderly, the Mini Nutritional Assessment was also utilized [13].

For the assessment of food intake, we used the three day food record, and direct observation on a weekend day. Information about the time, composition, consistency and amount of food eaten at every meal of the day was recorded. The composition of the meal was recorded according to the menu before being served. The amounts were recorded in household measures, at the moment when the kitchen staff served portions of food in the dining room. Immediately following the meal, the difference between what had been served and what remained was calculated in household measures, thus providing the intake. This quantitative consumption was converted into grams according to a chart of household measures. These values were then converted into calories and nutrients using DietWin ${ }^{\star}$ (DietWin Nutrition Software) and various food composition tables. After three days of recording, an average caloric and nutritional intake was obtained, which was then used in the study.

To calculate energy requirements, equations for Dietary Reference Intakes (DRIs) as proposed [14] were used. Macronutrient recommendations were calculated in accordance with the percentage distribution values based on the DRIs [14]. The recommendations for fatty acids and cholesterol were based on proposals [7].

We performed a qualitative assessment of nutrient intake, which was classified as insufficient, adequate or excessive according to sex and age. The probability $(\mathrm{P})$ of adequate intake (quantitative assessment) was also performed for the following nutrients: iron, zinc, niacin, thiamin, vitamins $\mathrm{B}_{6}$ and $\mathrm{B}_{12}$.

Statistical analysis consisted of descriptive analysis and chi-square test, Fisher's exact test and ANOVA to determine the factors associated with nutritional status, assessed by BMI and MAN. In addition, we used multinomial logistic regression analysis and the decision tree.

For entering predictor variables in the multinomial logistic model, a significance level of $25 \%$ was used. The variables were adjusted to the model by the backward stepwise method, using a significance level of $5 \%$.

The decision tree was the second method of multivariate analysis used to describe the factors that contributed to the occurrence of nutritional disorders. This method is based on classification rules based on a decision tree. The tree starts with a root node, with all the observations in the sample, and the subsequent branches represent subdivisions and subsets of data. This subdivision allows the identification of homogeneous subgroups of individuals for the systematic comparison of their characteristics. The division process is repeated until none of the selected variables show significant influence on the division or when the size of the subset is very small [15]

For all analyses, we adopted a 5\% level of significance using the Statistical Package for Social Sciences, version 17.0.

This study was approved by the Research Ethics Committee of the Federal University of Minas Gerais. All individuals signed a consent form, and for those who were unable to write, a finger print was obtained.

\section{Results}

Of the 55 seniors sampled, three declined to participate in the survey, so that the final sample included 52 elderly (94.5\%), and 55.3\% of the total number of elderly who were institutionalized.

Demographic data revealed that the subjects had a mean age of 76.6 \pm 9.0 years: $82.7 \%$ were female, and $40.4 \%$ had no schooling. Of the total, $46.2 \%$ were single, $40.4 \%$ had children, $57.7 \%$ rarely had visitors and $84.6 \%$ contributed $70 \%$ of their income to the ILPI.

With regards to mobility, $23.1 \%$ were confined to bed or wheelchair, while $55.8 \%$ had normal mobility. As for oral health, the use of dentures was observed in $19.2 \%$ of subjects, partial denture in $32.7 \%$ and $38.5 \%$ were edentulous without the use the dentures.

The mean and median number of comorbidities was 4 , with a minimum of one and maximum of seven diseases per person. The most prevalent diseases and health problems were hypertension - $(75.0 \%)$, psychiatric disorders (53.8\%) and osteoporosis / osteoarthritis (26.9\%).

Table 1 shows the variables related to nutritional status. According to BMI, the prevalence of overweight was $46.1 \%$ and underweight, $23.1 \%$. On the other hand, the prevalence of malnutrition, according to the MAN classification, was $7.7 \%$ and the risk of malnutrition of $67.3 \%$.

\begin{tabular}{lcc}
\hline & n & Percentage (\%) \\
\hline Body Mass Index & - & - \\
Underweight & 12 & 23,1 \\
Overweight & 24 & 46,1 \\
Mini Nutrition Assessmet & - & - \\
Risk for malnutrition & 36 & 67,3 \\
Malnutrition & 4 & 7,7 \\
Calf circumference & - & - \\
Muscle loss & 11 & 21,2 \\
Arm Muscle Area & - & - \\
Severe muscle deficit & 11 & 21,2 \\
Deficit mild muscle & 7 & 13,5 \\
Normal muscle & 30 & 57,7 \\
Excess muscle & 2 & 3,8 \\
Muscle increased & 2 & 3,8 \\
Waist circumference* & - & - \\
Very high risk of complications associated with obesity & 21 & 56,8 \\
High risk of complications associated with obesity & 4 & 10,8 \\
Waist/Hip ratio* & - & - \\
Risk of cardiovascular disease & 26 & 70,3 \\
\hline
\end{tabular}

*15 individuals without information (wheelchair)

Table 1: Nutritional status and risk for metabolic diseases of the elderly of the institution. 
Loss of muscle mass was observed in $21.2 \%$ of subjects, according to $\mathrm{CP}$ and $\mathrm{AMBc}$. According to the CC classification, 59.4\% of the seniors were at risk of complications associated with obesity and $70.3 \%$, according to the WHR, were at risk of cardiovascular disease.

According to the dietary assessment (Table 2), $17.3 \%$ of the elderly showed excessive caloric intake, while $11.5 \%$ had inadequate intake, the average daily intake being $1,530.61 \mathrm{kcal}$, ranging from 993.80 to 2432.81 $\mathrm{kcal}$. The consumption of fats, polyunsaturated and monounsaturated fatty acids was shown to be inadequate in almost all individuals.

There was a significantly insufficient intake of potassium (100\%), zinc $(82.7 \%)$ and niacin $(65.4 \%)$ in the study group. as well as excessive consumption of vitamin B6 (84.6\%) and B12 (51.9\%). The probability of adequate iron intake was $68.0 \%$ and that of zinc was $33.0 \%$. With regards to vitamins, the probability of adequate intake varied between $46 \%$ and $67 \%$.

In the multinomial multivariate analysis, no variable was statistically associated with nutritional status, whether measured by BMI or by MAN $(\mathrm{p}>0.05)$.

In the decision tree analysis, with BMI as the response variable (Figure 1), we found that all seniors, 65 years old or more having some form of mobility restriction, and taking the frequency of visits into consideration, were underweight. But for those with mobility problems, older than 65 years and who rarely had visitors, the prevalence of underweight decreased to $40 \%$. On the other hand, for those elderly receiving weekly, fortnightly or monthly visits, this percentage dropped to $16.7 \%$ and for those with normal mobility to $10.3 \%$.

However, among older people 91 years or less with normal mobility, the prevalence of overweight subjects was high (62.1\%), while those with normal mobility and more than 91 years were all eutrophic (Figure 1).

In the decision tree, with MAN as the response variable (Figure 2), the younger patients ( $\leq 78.5$ years) showed higher risk of malnutrition (100\%), while those older (> 78.5 years) were at lower risk $(50 \%)$, yet were more likely to be malnourished (50\%). On the other hand, none of the elderly aged less than 78 years and who had normal mobility or able to stroll, but were unable to walk outside of the ILPI, displayed malnutrition; however, $54.5 \%$ were at risk of malnutrition.

For the elderly with normal mobility or able to stroll, but were

\begin{tabular}{lllll}
\hline & \multicolumn{3}{l}{ Consumption (\%) } & \\
\cline { 2 - 5 } & Insufficient & Suitable & Excessive & Probability (\%) \\
\hline Calories & 11,5 & 71,2 & 17,3 & - \\
Protein & 5,8 & 94,2 & 0,0 & - \\
Lipid & 100,0 & 0,0 & 0,0 & - \\
Saturated Fatty Acid & 0,0 & 88,5 & 11,5 & - \\
Monounsaturated Fatty & 98,1 & 1,9 & 0,0 & - \\
Acid & 100,0 & 0,0 & 0,0 & - \\
Polyunsaturated Fatty Acid & 10,0 & - \\
Cholesterol & 0,0 & 100,0 & 0,0 & - \\
Iron & 13,5 & 71,2 & 15,4 & 68,0 \\
Potassium & 100,0 & - & - & - \\
Zinc & 82,7 & 11,5 & 5,8 & 33,0 \\
Thiamine & 23,1 & 26,9 & 50,0 & 51,0 \\
Niacin & 65,4 & 23,1 & 11,5 & 46,0 \\
Vitamin $B_{6}$ & 5,8 & 9,6 & 84,6 & 67,0 \\
Vitamin $B_{12}$ & 44,2 & 3,8 & 51,9 & 56,0 \\
\hline
\end{tabular}

Table 2: Qualitative and quantitative adequacy of micronutrient intake of the elderly of the institution.

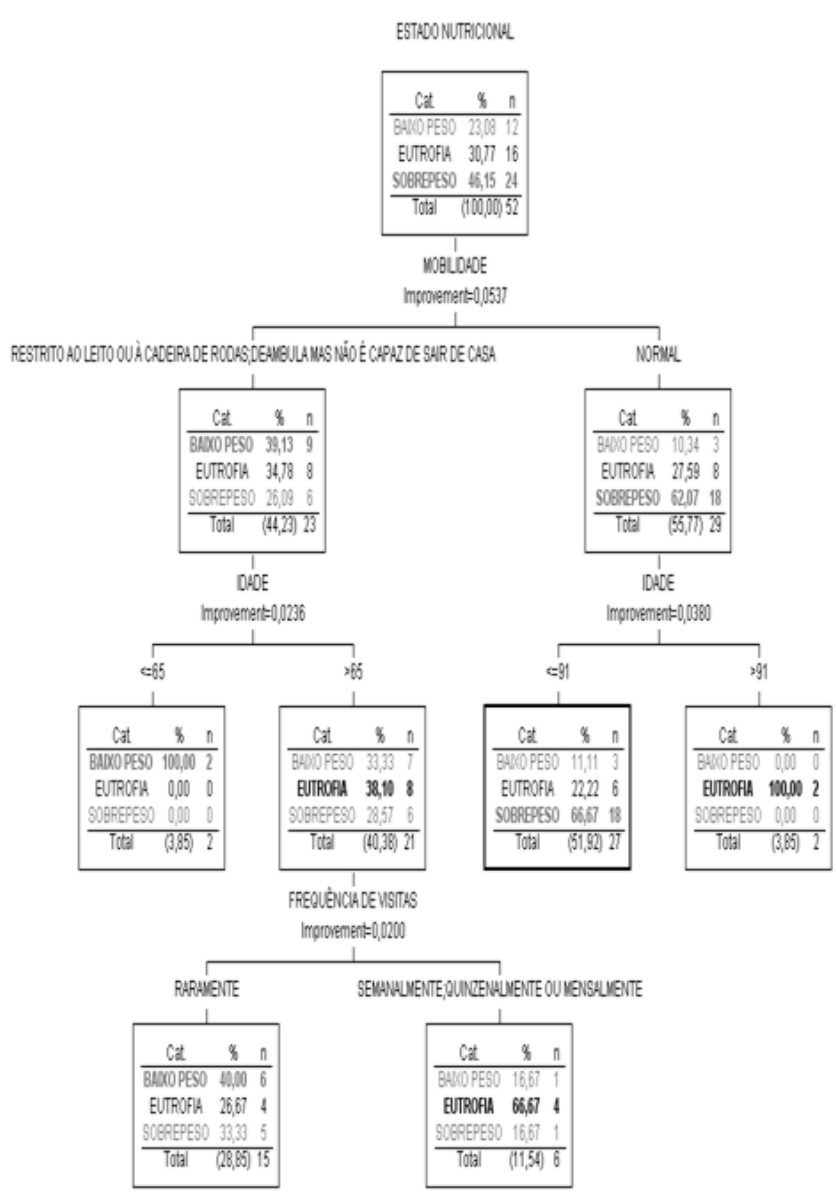

Figure 1: Decision tree (CART algorithm) with the response to nutritional status measured by Body Mass Index.

unable to walk outside the ILPI and older than 78.5 years, the risk of malnutrition was $66.7 \%$ and the prevalence of malnutrition of $16.7 \%$. In this situation, when financial contribution was taken into consideration, $21.4 \%$ of seniors who contributed $70 \%$ of their income had good nutritional status, while $71.4 \%$ were at risk of malnutrition. However, when this contribution rose to $100 \%$ of retirement income, this situation was reversed, rising to $50.0 \%$ of the elderly showing malnutrition, while the remaining 50\% were at risk of the disease (Figure 2).

\section{Discussion}

In this study both a high prevalence of overweight (46.1\%), according to BMI, and risk of malnutrition (67.3\%), according to MAN, were verified, concomitant with reduced muscular reserve and excess abdominal adiposity. The consumption of nutrients, although insufficient, especially for vitamins and minerals, was not associated with nutritional status, or with socioeconomic data. On the other hand, the mobility of the elderly, their financial contribution to the ILPI and frequency of visits were important factors in understanding their nutritional status. This demonstrates the importance of promoting care practices through health promotion with the elderly and families to improve their nutrition and quality of life.

The prevalence of underweight and overweight according to BMI was similar to that reported by other studies [16-17]. Similarly, 


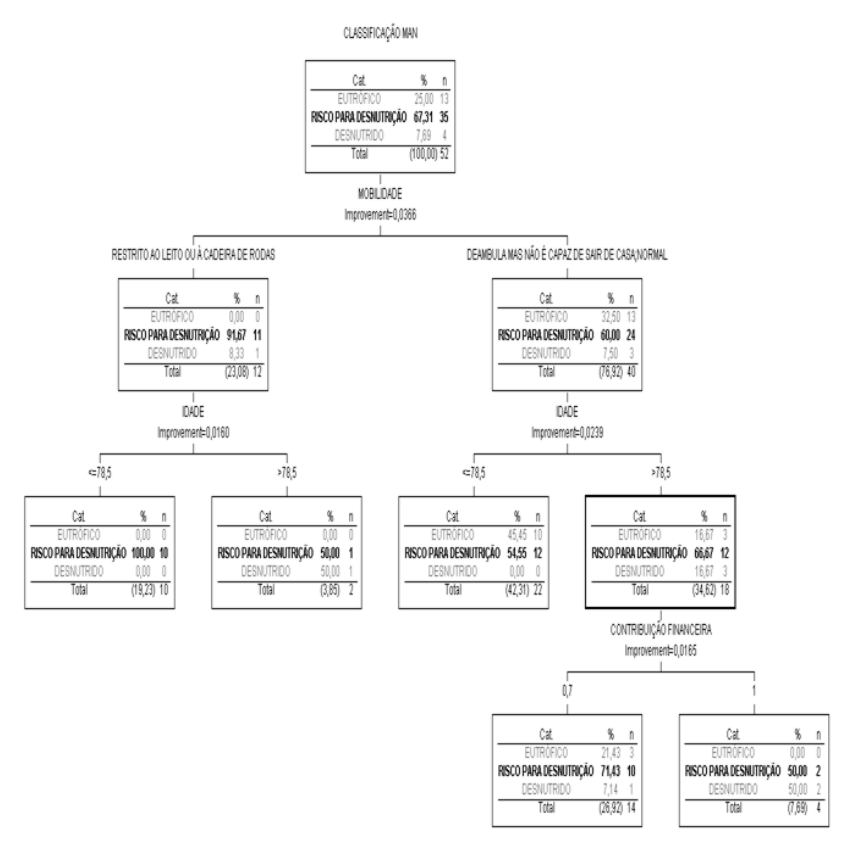

Figure 2: Decision tree (CART algorithm) with a response to the classification of Mini Nutritional Assessment.

prevalence of abdominal obesity as measured by WC and WHR [16] was also reported. It is noteworthy that, independent of excess weight, abdominal fat has an important impact on cardiovascular disease and is often associated with the occurrence of dyslipidemia, hypertension, insulin resistance and diabetes, especially among the elderly [6-17].

Nutritional status, assessed using MAN, showed results similar to those found another study ${ }^{[4]}$, where the prevalence of malnutrition was $8.3 \%$ and that of risk, $55.6 \%$. However, the study in the province of Ourense, the risk of malnutrition was similar (57.5\%), but the prevalence of malnutrition slightly higher (12.5\%) [18].

Corroborating the findings related to nutritional status, the elderly showed considerable percentage of reduction in muscle mass, as measured by $\mathrm{CP}$ and $\mathrm{AMBc}$. This decline negatively impacts the health of elderly people, especially for those who are institutionalized, and is perhaps associated with the occurrence of diseases such as tuberculosis and obstructive lung diseases. In addition, muscle weakness may develop, preventing the elderly from performing daily activities such as rising from a chair or carrying objects [19].

There was high prevalence of overweight and high risk of diseases associated with obesity and cardiovascular disease according to BMI, WC and WHR. BMI is highly correlated with body weight and has proximity to the body energy stores, without predicting the distribution of fat corporal [1].

On the other hand, MAN which predicts about the risk of developing malnutrition, showed a high rate of elderly at risk, pointing to the need for nutrition interventions. In assessing the factors contained in MAN, which contributed to the diagnosis of malnutrition risk in the institutionalized elderly, Ruiz-Lopez and colleagues [20] found a high proportion of risk of malnutrition related to factors related to lifestyle, medication and mobility.

In multinomial logistic regression analysis found no model, possibly because it was not able to detect differences. Therefore, we opted for a second type of multivariate analysis, which is the Classification and Regression Tree. This analysis is used to describe the factors that contribute to the occurrence of tomographic changes. The adjustment of the final model was evaluated by estimating risk, which indicates the extent to which the tree correctly predicts the results, comparing the difference between the adjusted value estimated by the model and the actual value observed in the sample [21].

The nutritional status, as identified by BMI and MAN, proved to be associated with mobility, frequency of visits and financial contribution by the elderly to the ILPI. The very old people with reduced mobility and who received fewer visits had a higher prevalence of low weight, possibly due to decreased access to food.

Elderly with mobility impairments have lower performance in the ability to perform activities of daily living and greater dependence on care, including meals and purchase of food [19]. The results of the Health, Welfare and Aging in Latin America and the Caribbean Project, which evaluated 2.143 elderly in São Paulo, revealed that the activities most affected for both sexes was the ability to make unaccompanied excursions outside of the home and shopping for foodstuffs [22]. Thus, we can see the importance of the care provided by nursing staff, in providing support in meeting mobility needs and principally those related to eating, given the influence on nutritional status.

On the other hand, the elderly who were more independent, who received more frequent visits and contributed financially less of their income to the ILPI had better nutritional status, perhaps due to the fact that they could complement their diet and consequently had access to a better supply of nutrients.

The reduction of the prevalence of being underweight in the elderly due to the frequency of visits or a lower contribution can be understood to result from a possibly greater access of the elderly to foods that complements the diet available from the ILPI. Aside from generating positive emotions, visitors may also provide food, improving the supply of calories and nutrients offered. This indicates the importance of the participation of families in the social life of the elderly, because social support has a positive influence on their eating habits and health status [23]. In addition, studies [24,25] show that having close friends makes a positive impact on mental and physical health of the elderly. Emphasized the importance of the multidisciplinary team as a source of encouragement to build friendships, since this relationship is an effective factor against loneliness, depression and immobility.

On the other hand, the lower financial contribution to the ILPI in terms of percentage of income favors purchase of complementary foods by the elderly, given the greater availability of funds. However, this condition may be compromised by mobility difficulties that some of the elderly may face.

It should be noted, however, that younger patients with preserved mobility had a higher prevalence of overweight. It is noticed that on one hand, greater access to food reduced the prevalence of underweight; it also seemed to favor an increase in overweight. This reveals the importance of promoting healthy dietary practices among those who retain functional mobility, as well as among visitors, in order to improve the adequacy of complementary feeding and to control food intake by elderly people who have mobility difficulties.

The need to adopt healthy eating practices can also be observed in the analysis of nutrient intake. There were insufficient amounts of lipids, monounsaturated and polyunsaturated fatty acids, zinc, potassium, niacin and vitamin $B_{12}$, as well as a significant percentage of elderly patients with caloric intake below or above recommended levels, which 
can foster the emergence of new malnutrition and overweight cases, respectively.

The high prevalence of dental impairment, also observed in other studies [26], may have contributed to this low intake of nutrients because it is known that edentulism and prosthetic rehabilitation is associated with a decrease in the average intake of vitamins and minerals [5].

This imbalance in nutrient intake can prejudice the health of the elderly. The lipids in the diet are critical for the supply of energy, giving flavor to food, and the sensation of satiety, with consequent spacing between meals, as well as transmitting lipo-soluble vitamins and essential polyunsaturated fatty acids. However, the results of this study showed an imbalance in the ratio of fatty acids, with a predominance of saturated fat at the expense of monounsaturated and polyunsaturated fats, which may favor the occurrence of dyslipidemia and cardiovascular events, more common among the elderly [1]

Despite the significant findings, the study has no external inference and presents a limitation to small sample size. It should be noted, however, that the purpose of the study was to evaluate the reality of ILPI and compare it with the literature, to contribute toward knowledge in the area and implementation of changes that favor the health of the older people in question. For this, the identification of the importance of other issues, such as social, for the nutritional status of elderly people living in an ILPI, justifies this study, as well as others on this issue.

\section{Conclusion}

Given the vulnerability of the group added with changes in body composition that occur with aging highlight the importance of the classification of nutritional status based on BMI and MAN.

Continuing education must be applied with the aim of training professionals to meet the basic needs of the elderly, especially those related to mobility and feed.

The results also point to the need to promote healthy eating habits within the ILPI in order to increase the proportion of elderly patients with adequate nutritional status. For this, the active participation of the dietician and nursing staff, together with other professionals in the institution is essential in order to provide a healthy diet with adequate intake of nutrients specific to the elderly, as well as an appropriate focus on the social issues involved.

\section{References}

1. Silveira EA, Lopes ACS, Caiaffa WT (2007) Avaliação do Estado Nutricional de Idosos. In: KAC G, SICHIERI, R, GIGANTE DP Epidemiologia Nutricional. Rio de Janeiro: Atheneu Cap 6:105-125

2. Alibhai SM, Greenwood, C, Payette H (2005) An approach to the management of unintentional weight loss in elderly people. CMAJ 172: 773-80.

3. Santelle O, Lefevre AMC, Cevato AM (2007) Alimentação institucionalizada e suas representações sociais entre moradores de instituições de longa permanência para idosos em São Paulo, Brasil. Cad Saude Publica 23: 3061 3065.

4. Machado RSP, Coelho MASC (2011) Risk of malnutrition among Brazilian institutionalized elderly: A study wtih the Mini Nutritional Assessment (MNA) questionnaire. J Nutr Health Agin 15: 532-535.

5. de Andrade FB, Caldas Junior Ade F, Kitoko PM, Zandonade E (2011) The relationship between nutrient intake, dental status and family cohesion among older Brazilians. Cad Saude Publica 27: 113-122.
6. Villarino Rodríguez A, García-Linares MC, García-Fernández MC, GarcíaArias MT (2003) Evaluación dietética y parámetros bioquímicos de minerales en uncolectivo de ancianos de la provincia de León (España). Nutr Hosp18: $39-45$.

7. World Health Organization. (1998) Obesity: preventing and managing the global epidemic. Geneva: World Health Organization.

8. Chumlea WMC, Roche AF, Steinbaugh ML (1989) Anthropometric approaches to the nutritional assessment of the elderly. In: MUNRO, H.; DANFORD, D. E. Human Nutrition: Nutrition Aging and The Elderly. New York: Plenum Press 1989, Cap 6: 335-361.

9. Greer, Margolis, Mitchell (1992) Nutrition interventions manual for professionals caring for older Americans. Grunwald \& Associates, Washington, DC, 1-130.

10. Heymsfield SB, Mcmanus C, Smith, J, et al. (1982) Anthropometric measurement of muscle mass: revised equations for calculating bonefree arm muscle area. American Journal of Clinical Nutrition 36:680-690.

11. Frisancho AR (1993) Anthropometric Standers for the Assessment of Growth and Nutritional Status. 4 ed Michigan: Ann Arbor

12. World Health Organization (1995) Physical status: the use and interpretation of anthropometry. Report of a WHO Expert Committee. World Health Organ Tech Rep Ser 854: 1-452.

13. Guigoz Y, Vellas B, Garry PJ (1994) Mini Nutritional Assessment: a pratica assessment tool for granding nutritional state of elderly patients. Facts and Research in Gerontology 4: 15-59.

14. Institute of Medicine. Dietary Reference Intakes for Energy, Carbohydrate, Fiber, Fat, Fatty Acids, Cholesterol, Protein, and Amino Acids. Washington, DC: National Academy Press. 2002.

15. Breiman L, Friedman JH, Olshen RA, Stone CJ (1984) Classification and regression trees. Pacific Grove, Califórnia: Wadsworth and Brooks.

16. Santos MRDR, Mendes SCSM, Morais DB, Coimbra MPS, Araújo MAM, et al.(2007) Caracterização nutricional de idosos com hipertensão arterial em Teresina, PI. Revista Brasileira de Geriatria e Gerontologia10: 73-86.

17. Tinoco ALA, Brito LF, Santanna MSL, Abreu WC, Mello AC, et al. (2006) Sobrepeso e obesidade medidos pelo índice de massa corporal (IMC), circunferência da cintura (CC) e relação cintura/quadril (RCQ), de idosos de um município da Zona da Mata Mineira. Revista Brasileira de Geriatra e Gerontologia 9: 63-73.

18. Miguelez, JM, Salve CA, Bernardez MM (2009) Evaluación del riesgo nutricional mediante el MNA en una población anciana no institucionalizada. Archivos Latinoamericanos de Nutrición 59: 390-395.

19. Gonçalves LHT, Silva AH, Mazo GZ, Benedetti TRB, Santos SMA, et al. (2010) O idoso institucionalizado: avaliação da capacidade funcional e aptidão física. Caderno Saúde Pública 26: 1738-1746.

20. Ruiz-López MD, Artacho R, Oliva P, Moreno-Torres R, Bolanos J, et al (2003) Nutritional risk in institutionalized older women determined by the min nutritional assessment test: what are the main factors? Nutrition 19: 767-771.

21. Breiman L, Friedman JH, Olshen RA, Stone C (1984) Classification and Regression Trees. Pacific Grove, Califórnia: Wadsworth and Brooks.

22. Duarte YAO, Lebrão ML, Lima FD (2005) Contribuição dos arranjos domiciliares para o suprimento de demandas assistenciais dos idosos com comprometimento funcional em São Paulo, Brasil. Rev Panam Salud Publica17:370-378.

23. Salgueiro H, Lopes M (2010) A dinâmica da família que coabita e cuida de um idoso dependente. Rev Gaucha Enferm 31: 26-32.

24. Llobet MP, Ávila NR, Farrás JF, Canut ML, et al. (2011) Qualidade de vida felicidade e satisfação com a vida em anciãos com 75 anos ou mais, atendidos num programa de atenção domiciliária. Rev Latino-Am 19: 467-475.

25. Aday R, Kehoe G, Farney L (2006) Impact of Senior Center Friendships on Aging Women Who Live Alone. J Women Aging 18: 57- 73.

26. Roque FP, Bomfim FMS, Chiari BM (2010) Descrição da dinâmica de alimentação de idosas institucionalizadas. Rev Soc Bras Fonoaudiol 2010 15: 256-263. 